\title{
Migraciones internacionales y derecho internacional privado
}

\author{
International migration and private international law
}

\section{Carmen González Pedrouzo* y Myriam Díaz Stratta**}

* Escribana pública, Universidad de la República, Uruguay. Profesora titular de Derecho internacional Privado, Universidad CLAEH. Profesora adjunta de Derecho internacional Privado, Universidad de la República, Uruguay.

$\bowtie$ esc.carmengonzalez@gmail.com

https://orcid.org/0000-00016116-9406

** Doctora en Derecho y Ciencias Sociales, Universidad de la $\mathrm{Re}$ pública, Uruguay. Profesora de Derecho internacional Privado, Universidad CLAEH.

https://orcid.org/0000-00031786-2697

RECIBIDO: [16.9.2018]

ACEPTADO: [12.11.2018]

\section{Resumen}

El presente trabajo tiene por finalidad explorar los vínculos entre las migraciones internacionales actuales y el derecho internacional privado. Para ello, comienza por un breve análisis del fenómeno migratorio internacional, sus características y su evolución. A continuación, presenta una breve referencia histórica a partir de los orígenes del derecho internacional privado y su nacimiento como disciplina cuyo objeto es el estudio de las relaciones privadas internacionales con la finalidad de asegurar su continuidad jurídica. Posteriormente, examina cómo el derecho internacional privado moderno ha venido afrontando los problemas derivados de las migraciones internacionales, cuestionando hasta qué punto las soluciones existentes son adecuadas para encarar los problemas planteados por las nuevas formas de migración internacional y cómo incide en este análisis el respeto de los derechos humanos, lo que desdibuja las fronteras entre derecho internacional privado y derecho internacional público.

Palabras clave: migración, derecho internacional, instrumento internacional, derechos humanos.

\begin{abstract}
The purpose of this article is to explore the links between international migrations and Private International Law at the moment. With this aim, the
\end{abstract}


analysis will start with a brief reference of the international migration phenomenon, its characteristics and its evolution. Next, we will refer briefly to the origin and subsequent birth of Private International Law as a subject whose object is the study of international private relationships and whose purpose is to ensure their juridical continuity. Then, an analysis will be done on the way modern Private International Law is facing the problems caused by international migrations, considering to what extent the present solutions are suitable to face the problems of the new ways of international migration and how the respect of human rights affect this analysis, blurring the frontiers between Private and Public International Law.

Keywords: migration, international law, international instruments, human rights.

\section{Introducción}

Los seres humanos han migrado durante miles de años, por distintas razones. Algunos lo han hecho - y siguen haciéndolo- para cubrir sus necesidades básicas; otros debido a catástrofes naturales o provocadas por los mismos seres humanos; otros por razones políticas, e incluso a otros los lleva el afán de buscar nuevas experiencias. Podría decirse que una de las características del ser humano es ser migrante. Ha migrado dentro de su país y también atravesando fronteras. En este último caso hablamos de migración internacional. Este trabajo — que no ingresará en formas peculiares de migración, como el asilo, el refugio, la deportación o la repatriación-, previa conceptualización de la migración internacional, se ubica en algunos de los problemas que la migración plantea y su relación con el derecho internacional privado (DIP).

Si se recuerda la definición de hecho jurídico del maestro Couture (1997), puede afirmarse que las migraciones son hechos jurídicos, por cuanto son eventos constituidos por acciones humanas, involuntarias o voluntarias, o por circunstancias de la naturaleza que crean, modifican o extinguen derechos. Los efectos jurídicos de las migraciones se han estudiado desde el ángulo de diversas disciplinas; entre ellas, el derecho internacional, que se ha preocupado particularmente por esta problemática, fundamentalmente con foco en los derechos humanos. Así, desde la segunda mitad del siglo $\mathrm{XX}$, $\mathrm{y}$ en especial en los últimos tiempos, se han aprobado importantes instrumentos internacionales que apuntan al respeto de los derechos de los migrantes.

Pero el derecho internacional privado, en tanto tiene por objeto asegurar la continuidad de las relaciones privadas internacionales - esto es, que las fronteras no constituyan un impedimento para el reconocimiento de las relaciones que se entablan entre las personas cuando actúan en el ámbito privado-, es la disciplina que tiene una vocación natural para abordar las consecuencias que el fenómeno migratorio genera 
en la vida de relación de quienes se desplazan más allá de las fronteras de su país de residencia.

\section{La migración internacional}

La migración internacional es definida por la Organización Internacional para las Migraciones (OIM) (2006, p. 40) como el «movimiento de personas que dejan su país de origen o en el que tienen residencia habitual, para establecerse temporal o permanentemente en otro país distinto al suyo».

A su vez, las Recomendaciones sobre Estadísticas de las Migraciones Internacionales de las Naciones Unidas (ONU, 1999, p. 32) han definido al migrante internacional como «toda persona que cambia de país de residencia habitual» y a esta última como «el país en el que vive la persona, es decir, el país en que la persona tiene una vivienda donde normalmente pasa los períodos diarios de descanso».

Hobsbawm (2016) indica que en el período 1846-1875 se registraron los movimientos migratorios más grandes de la historia hasta ese momento, cuando más de nueve millones de personas se desplazaron de Europa a Estados Unidos. Sin embargo, el siglo xx ha mostrado movimientos muchísimo mayores (impulsados, entre otras causas, por el desarrollo de los medios de comunicación), y más aún el siglo XxI. Así, el Informe 2018 sobre las migraciones en el mundo, de la OIM (2018), muestra que, mientras en 1970 el número de migrantes alcanzaba los 84.460.125, que representaban un 2,3\% de la población mundial, el número de 2015 alcanzó los 243.700.236, un 3,3\% de la población mundial. Esto significa que una de cada 30 personas en el mundo es migrante. El mismo informe también indica que la cantidad de hombres y mujeres está bastante equilibrada ( $52 \%$ de hombres y $48 \%$ de mujeres) y que alrededor de un $15 \%$ de los migrantes son menores de 19 años.

\section{El derecho internacional ante las migraciones. El derecho a migrar como un derecho humano}

Como dice Jayme (1995: 37), el leitmotiv que une a nuestra cultura jurídica contemporánea es el rol primordial de los derechos humanos. Estos han roto las barreras entre el derecho internacional privado y el derecho internacional público. Según este autor, el derecho internacional privado posmoderno se caracteriza por un regreso a cierto monismo del derecho internacional, por lo menos desde el punto de vista de la 
teoría del derecho, en el sentido de que la persona humana sigue siendo el centro del derecho.

Si bien ya en los Tratados de Montevideo de 1889 y 1940 (Tratado de Derecho, s.f.; Tratado de Montevideo, s.f.) se pueden encontrar normas que hoy consideramos integradoras para los migrantes, fue a partir de la segunda mitad del siglo xx que las migraciones comenzaron a ser objeto de interés para el derecho internacional con énfasis en los derechos humanos.

Así, en 1948, la Declaración Universal de los Derechos Humanos aprobada por las Naciones Unidas (ONU, 1948) consagró por primera vez el derecho a emigrar:

Toda persona tiene derecho a salir de cualquier país, incluso el propio, y a regresar a su país. (Artículo 13, numeral 2)

Posteriormente, esa misma disposición fue recogida por una norma vinculante como el Pacto Internacional de Derechos Civiles y Políticos de 1966 (ONU, 1966), del que cabe destacar el artículo 26:

[...] todas las personas son iguales ante la ley y tienen derecho sin discriminación a igual protección de la ley. A este respecto, la ley prohibirá toda discriminación y garantizará a todas las personas protección igual y efectiva contra cualquier discriminación por motivos de [...] origen nacional [...].

Si se pone dicho instrumento en perspectiva, considerando la realidad actual de las migraciones, que se traduce en el desplazamiento de personas pertenecientes a realidades culturales y religiosas diferentes, cobran especial interés varias disposiciones, entre las que puede destacarse el artículo 18:

Toda persona tiene derecho a la libertad de pensamiento, de conciencia y de religión; [...] Nadie será objeto de medidas coercitivas que puedan menoscabar su libertad de tener o de adoptar la religión o las creencias de su elección. La libertad de manifestar la propia religión o las propias creencias estará sujeta únicamente a las limitaciones prescritas por la ley que sean necesarias para proteger la seguridad, el orden, la salud o la moral pública, o los derechos y libertades fundamentales de los demás. (ONU, 1966)

También vinculado con estos derechos, el numeral 1 del artículo 24 constituye una disposición precursora de lo que luego sería la Convención sobre los Derechos del Niño: 
Todo niño tiene derecho, sin discriminación alguna por motivos de [...] origen nacional o social [...] a las medidas de protección que su condición de menor requiere, tanto por parte de su familia como de la sociedad y del Estado.

Posteriormente, el 13 de diciembre de 1985, la Asamblea General de las Naciones Unidas aprobó la Declaración sobre los Derechos Humanos de los Individuos que no son Nacionales del País en el que Viven (resolución 40/144), donde se establecen las obligaciones (artículo 4) y los derechos (artículos 5, 6 y 8) que corresponden a todo extranjero. Entre los derechos protegidos, se consagra el derecho a la vida y la seguridad de la persona, el derecho a la protección contra las injerencias arbitrarias o ilegales en la intimidad, la familia, el hogar o la correspondencia, el derecho a fundar una familia, el derecho a la igualdad ante los tribunales y demás órganos y autoridades encargados de la administración de justicia, el derecho a salir del país, el derecho a conservar su cultura, idioma y tradiciones (ONU, 1985).

Ya en diciembre de 1990, mediante la resolución 45/158, de 18 de diciembre de 1990, la Asamblea General de las Naciones Unidas adoptó la Convención Internacional sobre la Protección de los Derechos de Todos los Trabadores Migratorios y de sus Familiares (ONU, 1990), que entró en vigor el 1..$^{\circ}$ de julio de 2003. Este instrumento define en su artículo 2 lo que se entiende por trabajador migratorio: «toda persona que vaya a realizar, realice o haya realizado una actividad remunerada en un Estado del que no sea nacional». A su vez, se considera familiares a «las personas casadas con trabajadores migratorios o que mantengan con ellos una relación que, de conformidad con el derecho aplicable, produzca efectos equivalentes al matrimonio, así como a los hijos a su cargo y a otras personas a su cargo reconocidas como familiares por la legislación aplicable o por acuerdos bilaterales o multilaterales aplicables entre los Estados de que se trate» (artículo 4). A su vez, el artículo 12 reconoce el derecho a la libertad de pensamiento, de conciencia y de religión para los trabajadores migratorios y sus familiares.

Más recientemente, en la Declaración del Milenio (ONU, 2000a), para plasmar en acciones los valores fundamentales considerados esenciales para las relaciones internacionales en el siglo XxI (libertad, igualdad, solidaridad, tolerancia, respeto de la naturaleza y responsabilidad común), los jefes de Estado y de Gobierno reunidos en las Naciones Unidas el 8 de setiembre de 2000 se fijaron como uno de sus objetivos clave:

[...] adoptar medidas para garantizar el respeto y la protección de los derechos humanos de los migrantes, los trabajadores migratorios y sus familias, eliminar los actos de racismo y xenofobia cada vez más frecuentes en muchas sociedades y promover una mayor armonía y tolerancia en todas las sociedades. (Resolución $55 / 2$ ) 
Si se dirige la mirada hacia el continente americano, se advierte que la Declaración Americana de los Derechos y Deberes del Hombre, aprobada en Bogotá en 1948, consagró en su artículo viII la contracara del derecho a emigrar:

Toda persona tiene el derecho de fijar su residencia en el territorio del Estado de que es nacional, de transitar por él libremente y no abandonarlo sino por su voluntad. (OEA, versión 2015/1948)

En la Convención Americana sobre Derechos Humanos (Pacto de San José de Costa Rica, 1969) se prevé: «Toda persona tiene derecho a salir libremente de cualquier país, inclusive del propio» (artículo 22.2). Además, se reconoce el derecho a la libertad de conciencia y de religión, en la medida en que «nadie puede ser objeto de medidas restrictivas que puedan menoscabar la libertad de conservar su religión o sus creencias o de cambiar de religión o de creencia» (artículo 12.2). Por último, el artículo 24 proclama: «Todas las personas son iguales ante la ley. En consecuencia, tienen derecho, sin discriminación, a igual protección de la ley» (OEA, 1969).

En el ámbito del Mercosur, también se ha puesto de manifiesto el interés en regular la materia migratoria. Entre otros, se han celebrado acuerdos sobre exención de la traducción de documentos administrativos para la inmigración entre Estados partes y con los Estados asociados (Mercosur, 2000a), sobre residencia para nacionales de los Estados partes del Mercosur y asociados, y otros que aún no se encuentran en vigor, como el acuerdo para la creación de la visa Mercosur (2003) y sobre el tráfico ilícito de migrantes entre los Estados partes del Mercosur y con los Estados asociados (2004).

La apretada reseña que acaba de realizarse alude a compromisos asumidos por los Estados en torno a la protección de los derechos de quienes adoptan la decisión de abandonar su Estado de residencia con el propósito de establecerse en otro.

\section{El derecho internacional privado}

\section{Orígenes}

Si hay una disciplina jurídica cuya existencia misma se encuentra íntimamente vinculada con las migraciones internacionales, esa es el derecho internacional privado. En efecto, como se verá, los orígenes de esta rama del derecho — cuyo objeto es la relación privada internacional y su continuidad jurídica- se ubican alrededor del siglo XII en el territorio que hoy conocemos como Italia, con el crecimiento de las ciudades y, por ende, de la vida urbana. Allí comenzaron a desarrollarse no solo relaciones comerciales sino también vínculos de carácter familiar entre personas sometidas a 
leyes diferentes. Estas nuevas relaciones plantearon la necesidad de encontrar respuestas a las preguntas sobre cuál sería la ley aplicable y, eventualmente, cuál sería el juez competente para entender en los litigios que pudieran surgir.

La primera manifestación de migración que influyó en el establecimiento de las raíces de lo que hoy conocemos como derecho internacional privado fue la de las invasiones bárbaras. Estas marcaron un hito en cuanto a la coexistencia de distintos ordenamientos jurídicos (dentro del territorio romano ya no se aplicaría exclusivamente el derecho romano, sino que a partir de las invasiones este pasaría a convivir con las leyes de cada uno de los pueblos bárbaros) y determinaron lo que dio en llamarse la personalidad de las leyes. A partir de entonces, las personas se regirían por la ley del pueblo al que pertenecían en virtud de su origen, y esa ley las acompañaría y regiría sus actos adondequiera que fueran. Esa situación se prolongó por varios siglos desde la caída del Imperio Romano, en el siglo VI.

Tras largo tiempo de relaciones entre personas pertenecientes a distintos pueblos, estas se fueron mezclando y se fue desdibujando la aplicación del derecho de origen. La situación fue propiciada también por el desarrollo de las ciudades y fomentada por el tratado conocido como la Paz de Constanza, suscrito en esa ciudad en 1183 entre el emperador Federico Barbarroja y las ciudades lombardas, por el cual se les otorgó a estas, entre otras cosas, autonomía legislativa. Así, el criterio que para regular las relaciones entre las personas atendía al origen (que podría asimilarse a lo que hoy conocemos como nacionalidad) fue sustituido por el del domicilio.

A partir del siglo XII, en la región de Lombardía, con la creación de la Universidad de Bolonia, se estudió el derecho romano justinianeo mediante la técnica de glosas. Se procuraba encontrar en aquellas normas el sustento para resolver las dificultades que planteaban las nuevas situaciones en que participaban sujetos pertenecientes a distintas ciudades. Esto marcó el origen del derecho internacional privado moderno. En esta etapa, los estudiosos ponían el énfasis en el estudio de las normas y su alcance: se preguntaban si las normas de las ciudades tenían efecto exclusivamente dentro de la ciudad que las había dictado o si podían extender sus efectos más allá.

\section{El derecho internacional privado clásico: Story, Mancini y Savigny}

Habría que esperar hasta el siglo XIX para poder hablar con propiedad del nacimiento del derecho internacional privado tal como lo conocemos en la actualidad. Pero en el tiempo transcurrido hasta entonces no se detuvo el movimiento constante de personas entre las ciudades (y a partir de los siglos XV y XVI entre los Estados), así como tampoco se detuvo el interés por estudiar y encontrar respuestas a la regulación de las relaciones que se entablaban entre quienes habitaban en las ciudades de forma 
permanente y los forasteros. En este lapso se mantuvo el enfoque basado en la territorialidad o extraterritorialidad de las leyes. Fue en el siglo XIX cuando coincidieron tres autores clásicos, pertenecientes a realidades geopolíticas diferentes, cada uno con características distintivas, que dejaron una marca significativa en el derecho internacional privado moderno.

\section{Story}

Como señala Alfonsín (1982), esta disciplina es relativamente moderna; tan moderna, dicen Batiffol y Lagarde (1981), como su denominación, que puede remontarse al tratado de Joseph Story (jurisconsulto y profesor de la Universidad de Harvard) denominado Commentaries on the Conflict of Laws, Foreign and Domestic, publicado en 1834. Story, inspirado en el pensamiento del autor estatutario holandés (territorialista) Ulrico Huber, formuló tres axiomas que parten del territorialismo estricto de la ley, basado en la soberanía absoluta del Estado, único legitimado para crear normas jurídicas obligatorias dentro de su territorio.

En el primer axioma afirmó que dentro del territorio del Estado se aplicaba su ley a todos; no obstante, en el tercero manifestó: «La eficacia que los derechos de un país tienen en otros depende solo de los derechos de los últimos sobre la base de sus expresos o tácitos consentimientos» (Boggiano, 1981, p. 24). Al igual que lo hacía Huber, Story consagró aquí el concepto de comity (cortesía), por el cual admitía que, en ciertas situaciones, si se consideraba conveniente, los tribunales de un Estado pudieran aplicar un derecho extranjero. No obstante, esa aplicación no constituía una obligación jurídica, sino que se trataba de una aplicación facultativa del derecho extranjero.

Esta posibilidad de aplicar el derecho extranjero que planteaba Story fue criticada por teorías angloamericanas posteriores, desarrolladas entre fines del siglo XIX y comienzos del siglo $\mathrm{xx}$, tales como la teoría de los derechos adquiridos (sustentada principalmente por Dicey y Beale en Inglaterra y Estados Unidos respectivamente) o la teoría del derecho local (representada fundamentalmente por Lorenzen y Cook), que se aferraban a la territorialidad estricta del derecho. No obstante, incluso estas teorías debieron valerse de subterfugios - como el reconocimiento de los derechos subjetivos en lugar del derecho objetivo en el caso de la primera o la creación de una norma local idéntica al derecho extranjero en el caso de la segunda- para explicar la aplicación de ese derecho extranjero sin abdicar del territorialismo estricto que proclamaban, cuando las situaciones que involucraban elementos extranjeros lo ameritaban, de modo de no perjudicar los intereses del Estado o de los particulares. Estas teorías obedecieron en muy buena medida a las situaciones generadas por el movimiento inmigratorio que se produjo en la época en los Estados Unidos de América. 


\section{Mancini}

También en la Europa del siglo XIX los movimientos migratorios ejercieron una influencia decisiva en la construcción del derecho internacional privado. Ya en el Código Civil francés de 1804 se consagró (en una norma que continúa vigente) que la ley francesa regía el estado y la capacidad de los franceses aun cuando residieran en el extranjero (artículo 3, inciso 3..$^{\circ}$ ). De esta manera, los emigrantes franceses seguían unidos a su país de origen en todo lo que refería a su estado y capacidad.

En el mismo sentido, Pasquale Estanislao Mancini, jurista y político italiano del siglo XIX, autor de la obra La nacionalidad como la base del derecho internacional, postuló el criterio de la nacionalidad y lo utilizó como herramienta política para lograr la unificación italiana. Según recuerda Alfonsín (1982, p. 152), Mancini sostuvo que «la condición cosmopolita del hombre lo lleva a cruzar fronteras, a transitar por países extranjeros o a establecerse en el exterior», y esto es lo que provoca conflictos de leyes. Si los individuos permanecieran dentro del territorio del Estado del que son nacionales, ese tipo de conflictos no se suscitaría. No obstante, para Mancini, las normas relativas al estatuto personal integraban el orden privado del extranjero, que debía ser respetado por el Estado receptor.

\section{Savigny}

Fue en Alemania donde tuvo lugar lo que se considera el nacimiento del derecho internacional privado moderno, de la mano del jurista Friedrich Karl von Savigny. Este autor, estudioso del derecho romano, en el tomo viII del Sistema del derecho romano actual, publicado en 1849, propuso un cambio radical en el análisis de estas relaciones que traspasaban las fronteras de los Estados: el núcleo del problema estaba en la propia relación jurídica, no en la ley. Y este es el enfoque actual de las cuestiones privadas internacionales.

Para este autor, toda relación, por su naturaleza, tiene un asiento territorial (Sitz), una sede, un vínculo con un lugar y, por ende, con un derecho estatal determinado. El problema radica, precisamente, en determinar ese derecho, único y adecuado, con el que la relación tiene ese vínculo. Y la metodología para determinarlo es la llamada norma de conflicto, esto es, una norma jurídica cuya única función consiste en señalar el derecho del Estado en el que la relación jurídica tiene su asiento. Para aquellas categorías jurídicas vinculadas a la persona, como la capacidad y el derecho de familia, Savigny (trad. 2004/1849) encontró ese asiento territorial en el domicilio. En efecto, buscando el principio jurídico que somete a un individuo a un derecho determinado, reflexionó en el sentido de que, mientras en el derecho romano ese principio era el derecho de ciudadanía en una ciudad, en el derecho actual el principio que somete a un individuo a un derecho determinado es el domicilio. Sostenía que el criterio del domicilio había suplantado al de la nacionalidad y que entre las causas de ello debía 
colocarse en primer lugar el desarrollo de las comunicaciones activas y multiplicadas de los pueblos entre sí, que llevaban a hacer desaparecer las diferencias más importantes entre las nacionalidades.

\section{Las migraciones internacionales y su impacto en la codificación del derecho internacional privado}

La situación demográfica del continente europeo en el siglo XIX determinó que la postura de Mancini tuviera una influencia decisiva en las codificaciones de la región en esa época. Al adoptar el criterio de la nacionalidad, los Estados se aseguraban de que los individuos siguieran unidos al Estado de origen mediante la aplicación de su ley a todas sus relaciones de carácter personal, aun encontrándose a miles de kilómetros y mucho tiempo después de haber emigrado. Esto tuvo como corolario que la doctrina iusprivatista europea incluyera el derecho de extranjería como un capítulo del derecho internacional privado. Así, Esteban de la Rosa (2007, p. 108) ha sostenido que, si bien las relaciones entre el sistema de derecho internacional privado y el ordenamiento de extranjería e inmigración han sido siempre estrechas, en determinado momento histórico se consideraba que el derecho de extranjería formaba parte del contenido del primero. Y agrega:

[...] en la actualidad puede hablarse de la interrelación entre ambos sistemas, pues la inmigración no agota sus perfiles en su dimensión jurídico-pública (en particular, administrativa, aunque no solo), sino que las situaciones privadas (en particular, vinculadas con el ámbito personal y familiar) son cada día más relevantes.

Ya en el siglo xx, la Conferencia de La Haya sobre Derecho Internacional Privado también aceptó el criterio de la nacionalidad en diversos instrumentos (solo por mencionar algunos, los convenios de 1956 sobre ley aplicable a las obligaciones alimentarias, de 1961 sobre protección de menores, de 1961 sobre formas testamentarias, de 1965 sobre adopción y de 1978 sobre regímenes matrimoniales) y, tratándose de un foro internacional con representación de Estados de todos los continentes, hasta intentó - sin mayor éxito - dirimir los conflictos entre la ley nacional y la ley del domicilio mediante un Convenio (Hague Conference on Private International Law, trad. 2008, 2008b, 2008c, 2008d, 2008e, 2008f).

Por su parte, los Estados americanos en el siglo XIX eran receptores de migrantes, y fue allí donde los postulados de Savigny tuvieron mayor eco. Los Tratados de Montevideo de 1889 — primeros instrumentos de derecho internacional privado en entrar 
en vigor en el mundo- no solo adoptaron la metodología conflictualista, sino también el criterio del domicilio como ley aplicable a todas las cuestiones vinculadas con el estatuto personal. Las mismas soluciones fueron adoptadas cincuenta años más tarde en los Tratados de Montevideo de 1940 y, en el caso de la República Oriental del Uruguay, en la ley 10.084, de 3 de diciembre de 1941, incorporada como apéndice al Código Civil. Aun en la actualidad, el proyecto de Ley General de Derecho Internacional Privado, que se encuentra a estudio del Parlamento, consagra este mismo criterio. Se trata de soluciones integradoras, que eliminan toda distinción en la regulación de las relaciones privadas de carácter personal entre nacionales y extranjeros.

En un sentido similar, merece mención especial otra obra codificadora relevante: el Código de Derecho Internacional Privado aprobado en La Habana el 20 de febrero de 1928, conocido como Código Bustamante (1928), que contempló el criterio de la nacionalidad y, tratando de conciliar ambos criterios, incluyó esta disposición:

Cada Estado contratante aplicará como leyes personales las del domicilio, las de la nacionalidad o las que haya adoptado o adopte su legislación interior. (Artículo 7, Convención de Derecho Internacional Privado, s.f./1928)

Puede deducirse que la tensión entre el criterio de la nacionalidad y el criterio del domicilio ha dominado la historia del derecho internacional privado, considerando la política legislativa de los Estados basada fundamentalmente en su situación de países de inmigración o de emigración.

\section{El punto de conexión residencia habitual como criterio convergente}

Pese a que buena parte de los Estados americanos, particularmente de América Central y del Sur, se han transformado en países de emigración, las normas de derecho internacional privado han mantenido el punto de conexión domicilio como determinante de la ley aplicable a las relaciones jurídicas que forman parte del estatuto personal. No obstante, este concepto, que en la concepción clásica estaba integrado por un elemento objetivo (residencia habitual) y uno subjetivo (el ánimo de permanecer), ha tendido a hacerse exclusivamente objetivo mediante la eliminación del requisito del ánimo, con lo que ha pasado a identificarse con la residencia habitual. Ejemplo de esto es, en nuestro continente, la aprobación de la Convención Interamericana sobre Domicilio de las Personas Físicas (1979), que a los efectos de definir este punto de conexión fija como primer criterio el Estado de la residencia habitual de la persona (OEA, s.f.a/1979). Igualmente, las modernas soluciones en materia de protección de meno- 
res, tanto en el ámbito universal (como la Conferencia de La Haya) como americano, se han inclinado por este punto de conexión fáctico.

Si se observa lo ocurrido en los Estados europeos, la solución adoptada tradicionalmente - esto es, el criterio de la nacionalidad - ha tenido como consecuencia que en territorio europeo sean aplicables institutos que en algunos casos afectan principios esenciales de la identidad jurídica de esos Estados (orden público internacional). Situaciones de este tipo ocurren, por ejemplo, en casos en los que el derecho aplicable es el de un Estado islámico, particularmente cuando se trata de los derechos de las personas y del derecho de familia, donde el derecho islámico consagra soluciones que pueden resultar intolerables en el mundo occidental (limitaciones a los derechos de la mujer, repudio, etcétera). Esto fue advertido por Jayme (1995, p. 52), quien afirma que lo que caracteriza verdaderamente al derecho internacional privado actual son los conflictos de culturas. Este autor considera que el derecho islámico de la familia ha generado numerosos conflictos fuera de los países de tradición musulmana.

En cuanto al ingreso del islam por medio de la migración, Deprez (1988) critica el planteamiento actual del derecho internacional privado sosteniendo la necesidad de tomar en consideración aspectos sociológicos, frecuentemente desconocidos en la formulación tradicional de dicha disciplina.

También sobre la realidad europea actual y su impacto en el derecho internacional privado, Esteban de la Rosa (2007, p. 108) manifiesta:

[...] al sistema de DIPr se le plantean cuestiones nuevas, que obligan a repensar y reflexionar acerca del tradicional elemento de extranjería, dado que ya no es solo la nacionalidad sino la condición socio-económica de la persona inmigrante o inmigrada. Este sistema no ha de dar respuesta a las situaciones privadas internacionales caracterizadas por la pertenencia del sujeto a un grupo cultural determinado por razones de emigración (y su conservación en el Estado de acogida), sino a la circunstancia de que las personas emigrantes/emigradas tienen unas condiciones socio-económicas determinadas que requieren la atención del ordenamiento de cara a su integración e inserción socio-laboral. Para ello es necesario interpretar sus reglas de conformidad con la función de este nuevo sistema en el contexto general de la regulación de la inmigración.

No solo en legislaciones nacionales como la española o la francesa parece ir abriéndose paso el criterio de la residencia habitual, sino también en la normativa de la Unión Europea sobre derecho internacional privado. Ejemplos de ello son el reglamento 2201/2003, relativo a la competencia, el reconocimiento y la ejecución de resoluciones judiciales en materia matrimonial y de responsabilidad parental, y el más reciente Reglamento Sucesorio Europeo (650/2012) (Unión Europea, 2003, 2012). 
Parece, entonces, que está surgiendo una tendencia convergente de las legislaciones de los Estados que vendría a sustituir la famosa y tradicional dicotomía nacionalidad/domicilio mediante el criterio de la residencia habitual.

Esta solución también podría criticarse por implicar la absorción del extranjero por el Estado de acogida, al plantearse la aplicación del Estado de la residencia habitual y el no reconocimiento de la individualidad del inmigrante. No obstante, se entiende que debe primar la mirada favorable por su carácter no discriminador, dado que las relaciones personales de todos aquellos que viven en un mismo territorio se tratan de la misma manera, sin importar el origen étnico de las partes. Como dice Jayme (1995, p. 58), el derecho internacional privado, que permite dar cierta estabilidad a las familias integradas por ciudadanos de diversas nacionalidades mediante el reconocimiento transfronterizo de relaciones familiares, comparte igualmente uno de los fines más ambiciosos de la comunidad internacional, al poner sus normas al servicio de la paz. Y el punto de conexión residencia habitual puede contribuir a ello.

\section{Los problemas de las migraciones internacionales abordados por el derecho internacional privado actual}

\section{Las migraciones y la familia}

El fenómeno migratorio actual ha dado luz los problemas que la multiculturalidad plantea al derecho internacional privado, realidad que se pone de manifiesto principalmente en las cuestiones que afectan a las personas en su ámbito más íntimo: el familiar. El propio origen de la familia con formas no universalmente reconocidas, como la unión concubinaria o el matrimonio igualitario, las diversas formas de disolución del vínculo matrimonial o concubinario, los desafíos de la maternidad subrogada y formas «afines» a la adopción son ejemplos de los desafíos que hoy se plantean al derecho y que están estrechamente vinculados a la efectividad del respeto de los derechos humanos. Como indica Esteban de la Rosa (2007 p. 107):

[...] ya no es la mera puesta en contacto de una situación privada con una pluralidad de ordenamientos, sino que tales relaciones presentan también un factor socio-económico. Por tanto, el rasgo que caracteriza a las nuevas situaciones privadas internacionales vinculadas con la inmigración es la presencia de personas, de nacionalidad extranjera y de condición inmigrantes, que no pierden las relaciones con sus países de origen y, por tal motivo, sus vidas transcurren «a caba- 
llo» entre dos ordenamientos (el del país de acogida y de origen), lo que, en ocasiones, dificulta tales relaciones personales y familiares en ambos lugares.

Como reafirma Jayme (1995, p. 42) citando a Mancini, el lazo de una persona con determinada nación es lo que decide la ley aplicable a las cuestiones jurídicas que tocan más cerca a esa persona, y las relaciones de familia se consideran universales: no conocen fronteras etáticas.

En este sentido, pueden mencionarse las soluciones adoptadas por los Tratados de Montevideo, que, si bien no abordan las nuevas modalidades de familia por tratarse de instrumentos aprobados a fines del siglo XIX y mediados del siglo XX, sí recogen de modo amplio el reconocimiento de las relaciones de familia constituidas en el extranjero. Como ejemplo puede mencionarse el reconocimiento del matrimonio según la ley de celebración (con el límite impuesto por el orden público internacional en cuanto al instituto del matrimonio poligámico) y la admisión del régimen patrimonial del matrimonio de conformidad con la ley del Estado donde se estableció el primer domicilio conyugal. Igualmente, las soluciones vigentes en materia de reconocimiento de sentencias extranjeras permiten —en determinadas condiciones de carácter procesal, formal y material - reconocer disoluciones de la sociedad conyugal o del vínculo conyugal dictadas en el extranjero. Asimismo, la Convención de Nueva York de 1956, sobre la obtención de alimentos en el extranjero; las normas más modernas sobre obligaciones alimentarias, como las de la Convención Interamericana sobre Obligaciones Alimentarias (1989), o el más reciente Convenio de La Haya, de 2007, sobre cobro internacional de alimentos para los niños y otros miembros de la familia, consagran un amplio abanico de posibilidades que permiten a los familiares de migrantes reclamar alimentos desde su Estado de origen (ONU, 1957; OEA, s.f.b; Hague Conference on Private International Law, 2008g).

En términos generales, puede decirse que el derecho internacional privado aún no ha logrado brindar respuestas plenamente satisfactorias a la regulación de las nuevas formas de familia, fundamentalmente en lo que tiene que ver con la posibilidad de que sean reconocidas extraterritorialmente. Sin embargo, deben mencionarse los esfuerzos de la Conferencia de La Haya en materia de concubinato, filiación y maternidad subrogada, que, si bien aún no han logrado concretarse en textos normativos vinculantes, demuestran la preocupación de los Estados por llegar a soluciones uniformes en temas de gran sensibilidad para las personas (Conference de la Haye de Droit International Privé (2018a, 2018b). 


\section{La migración y los niños}

La información que llega día a día por los medios de prensa da cuenta de una importante cantidad de niños migrantes. Como se ha señalado, el Informe 2018 sobre las migraciones en el mundo (OIM, 2018) confirma que más de un sexto de los migrantes internacionales tienen menos de 19 años. Dentro de este número cabe incluir a los menores que viajan integrando el grupo familiar, pero también a aquellos no acompañados y aun aquellos que quedan en su país de origen separados de su familia, todos ellos en condiciones de vulnerabilidad.

Sin perjuicio de que los Tratados de Montevideo de 1889 y 1940 (Tratado de Derecho, s.f.; Tratado de Montevideo, s.f.) ya contemplaban la protección de los incapaces desde el punto de vista internacional, para lo que previeron soluciones que apuntaban a regular cuestiones de orden tanto personal como patrimonial, el Convenio de 1996 sobre Responsabilidad Parental y Medidas de Protección de Niños, aprobado en el ámbito de la Conferencia de La Haya de Derecho Internacional Privado (Hague Conference on Private International Law, 2008h), adoptó una solución más adecuada, por cuanto se basa en el criterio de la residencia habitual referido previamente, dejando de lado el criterio domiciliar consagrado en los Tratados de Montevideo.

Una disposición en particular, el artículo 6, merece especial atención, por cuanto establece que, respecto a los niños refugiados, los desplazados internacionalmente como consecuencia de desórdenes en sus países y aquellos cuya residencia habitual no pueda determinarse, las autoridades competentes para adoptar las medidas de protección de su persona o de sus bienes serán las del Estado en cuyo territorio se encuentren tras su desplazamiento. De esta manera se evitan las dificultades que puede presentar la regulación de la situación de niños que se encuentran en una situación de particular vulnerabilidad por carecer de residencia habitual en alguno de los Estados partes.

Las formas ilícitas de traslado o retención de menores en el ámbito familiar son otras modalidades de migración en las que participan niños. En estos casos, los niños viajan acompañando a alguno de los miembros del grupo familiar, pero ello se encuentra precedido de un acto ilícito determinado por la violación del derecho de guarda. Esta situación ha sido contemplada en tratados de alcance universal, como el de La Haya (1980), regionales, como la Convención Interamericana sobre Restitución Internacional de Menores (1989), y convenios bilaterales, como los celebrados por Uruguay con Argentina (1981), Chile (1982) y Perú (1984).

Más recientemente, en Uruguay, la ley 18.895, de 20 de abril de 2012, estableció el procedimiento para la restitución de menores de dieciséis años de edad que se encuentren en la República con motivo de un traslado o retención ilícitos de su centro habitual de vida, en violación de un derecho de guarda. 


\section{La migración y los delitos}

La multiplicación del fenómeno migratorio ha dado lugar también a la proliferación de actos delictivos, entre los cuales destaca el interés de obtener un beneficio material a cambio de trasladar personas interesadas en emigrar a un Estado determinado. Este tipo de conductas ha sido ubicado por las Naciones Unidas en el marco de la delincuencia transnacional organizada.

En diciembre de 2000 se aprobó la Convención de Palermo contra la Delincuencia Organizada Transnacional, instrumento que contiene disposiciones que contemplan la asistencia judicial internacional e incluso la extradición de quienes cometan los delitos comprendidos en la Convención y en sus protocolos complementarios (ONU, 2000b). Entre estos últimos cabe destacar el Protocolo contra el Tráfico Ilícito de Migrantes por Tierra, Mar y Aire, que se inspira en la necesidad de proteger los derechos humanos de los migrantes mediante un instrumento de alcance universal en el que los Estados asumen la obligación de tipificar el delito de tráfico ilícito de migrantes y otras conductas delictivas conexas (artículo 6).

\section{El acceso de los inmigrantes a la justicia}

El acceso a la justicia es uno de los derechos más importantes que se puede reconocer a una persona. Y es que, de no poder acceder a la justicia, los demás derechos serían letra muerta. En efecto, todas las normas protectoras de los migrantes y sus familias a las que acabamos de hacer referencia se reducirían a declaraciones de buenas intenciones si no se garantizara el acceso de las personas a los tribunales. El informe del Programa de las Naciones Unidas para el Desarrollo (PNUD) sobre acceso a la justicia (UNDP, 2004, p. 6) afirma que este es mucho más que mejorar la posibilidad de que un individuo llegue a los tribunales o garantizar la representación legal, porque debe asegurar que los resultados jurídicos y judiciales sean justos y equitativos. Por eso concordamos con Vescovi (2000, p. 19) cuando señala que este principio del derecho procesal internacional se encuentra íntimamente vinculado con el derecho a la defensa letrada y con la gratuidad, así como con la no discriminación del litigante foráneo. La importancia de este derecho amerita detenerse en algunos de estos aspectos y en cómo los aborda el derecho internacional privado.

\section{La condición procesal del litigante foráneo}

Durante mucho tiempo, los inmigrantes estuvieron sometidos a una discriminación puesta de manifiesto en institutos tales como la fianza de arraigo (cautio iudicatum solvi). Esta figura fue definida por Couture (1997, p. 288) como la «garantía real o personal que debe prestar, a solicitud del demandado, el actor que no tiene domicilio 
ni bienes en la República, para asegurar el pago de las costas y daños derivados del juicio, a los que eventualmente pudiera ser condenado». Como señala Tellechea (2011), en el plano doctrinario fue el Instituto de Derecho Internacional, en su sesión de Zúrich, en 1877, el que proclamó que el extranjero debería ser admitido en juicio en las mismas condiciones que el nacional, con lo que estableció una de las condiciones que facilitan el acceso del individuo a la justicia.

En el continente americano, una norma de derecho internacional privado fue la primera en eliminar la discriminación entre litigantes nacionales y extranjeros, mucho antes de que la Declaración Universal de los Derechos del Hombre, de 1948, consagrara el derecho de acceso a la justicia en su artículo 8; que el Pacto Internacional de Derechos Civiles y Políticos, de 1966, lo previera en su artículo 14, y que la Convención Americana de Derechos Humanos lo contemplara en sus artículos 7, 8 y 25 (ONU, 1948, 1966; OEA, 1969). Fue el Código Bustamante (no vigente para Uruguay), de 1928, que en su artículo 383 dispuso:

No se hará distinción entre nacionales y extranjeros en los Estados contratantes en cuanto a la prestación de la fianza para comparecer en juicio.

Más cercanos en el tiempo, merecen particular mención los convenios bilaterales sobre igualdad de trato procesal y exhortos suscritos por Uruguay con Argentina (1981), Chile (1982) y Perú (1985), por cuanto eliminan toda forma de discriminación entre los litigantes en razón de domiciliarse en un Estado distinto de aquel donde se desarrolla el proceso. Estos convenios bilaterales son un antecedente de las soluciones consagradas en el ámbito del Mercosur, a las que se hará referencia a continuación.

En el ámbito del Mercosur, en 1992, el Protocolo de Cooperación y Asistencia Jurisdiccional en Materia Civil, Comercial, Laboral y Administrativa (Protocolo de Las Leñas) en el ámbito del Mercosur consagró en su artículo 3:

Los ciudadanos y los residentes permanentes de uno de los Estados Partes gozarán, en las mismas condiciones que los ciudadanos y residentes permanentes de otro Estado Parte, del libre acceso a la jurisdicción en dicho Estado para la defensa de sus derechos e intereses.

Y el inciso $1 .^{\circ}$ del artículo 4:

Ninguna caución o depósito, cualquiera sea su denominación, podrá ser impuesta en razón de la calidad de ciudadano o residente permanente de otro Estado Parte. (Mercosur, 1992) 
Lo mismo fue consagrado en el Acuerdo de Cooperación y Asistencia Jurisdiccional en Materia Civil, Comercial, Laboral y Administrativa entre los Estados partes del Mercosur y la República de Bolivia y la República de Chile (decisión 8/02, Buenos Aires), que se encuentra en vigor entre Argentina, Brasil, Paraguay, Chile, Ecuador y Perú (Mercosur, 2002).

En el derecho procesal internacional de fuente nacional uruguaya, a partir de la entrada en vigor del Código General del Proceso (ley 15.982, de 18 de octubre de 1988), se eliminó la prestación de esa caución, que constituía un elemento de discriminación inaceptable con respecto a los litigantes extranjeros.

Más recientemente, la ley 18.250, de 6 de enero de 2008 (Ley de Migraciones), reconoce con carácter general:

[...] el derecho inalienable de las personas migrantes y sus familiares sin perjuicio de su situación migratoria [...] al debido proceso y acceso a la justicia [...] sin distinción alguna por motivos de sexo, raza, color, idioma, religión o convicción, opinión política o de otra índole, origen nacional, étnico o social, nacionalidad, edad, situación económica, patrimonio, estado civil, nacimiento o cualquier otra condición. (Artículo 1.²)

A los efectos de la aplicación de la ley, el artículo 3 define migrante como «toda persona extranjera que ingrese al territorio con ánimo de residir y establecerse en él, en forma permanente o temporaria». Y de manera expresa, la Ley de Migración prevé en su artículo 7:

[...] las personas extranjeras que ingresen y permanezcan en territorio nacional en las formas y condiciones establecidas en la presente ley tienen garantizado por el Estado uruguayo el derecho a la igualdad de trato con el nacional en tanto sujetos de derechos y obligaciones.

En particular, el artículo 9 precisa:

La irregularidad migratoria en ningún caso impedirá que la persona extranjera tenga libre acceso a la justicia [...].

\section{Gratuidad}

En el ámbito interamericano, normas procesales internacionales como las convenciones interamericanas sobre Exhortos o Cartas Rogatorias (1975), en sus artículos 8 y 12 (OEA, s.f.c); sobre Recepción de Prueba en el Extranjero (1975), en su artículo 7 (OEA, s.f.d), y sobre Medidas Cautelares (1979), en su artículo 16 (OEA, s.f.e), contem- 
plan la situación de quienes no pueden hacer frente a los costos del proceso o de la defensa letrada en el ámbito de la cooperación judicial internacional.

Aun tratándose de un texto del que Uruguay no es parte, merece una mención, por la importancia del foro en el que fue elaborado, el Convenio de La Haya para Facilitar el Acceso Internacional a la Justicia, de 25 de octubre de 1980, al que ha adherido Brasil. Conforme el inciso $1 .^{\circ}$ de su artículo 1. :

Los nacionales de un Estado contratante, así como las personas que tengan residencia habitual en un Estado contratante, tendrán derecho a disfrutar de asistencia judicial en materia civil y comercial en cada uno de los Estados contratantes en las mismas condiciones que si ellos mismos fuesen nacionales de ese Estado y residiesen en él habitualmente. (Hague Conference On Private International Law, 2008i)

A su vez, en el ámbito del Mercosur, en 1994, el Protocolo de Ouro Preto sobre Medidas Cautelares previó en su artículo 25 que la parte solicitante de la medida cautelar quedará exenta del pago de las costas judiciales y demás gastos cuando haya obtenido el beneficio de litigar sin gastos en el Estado requirente de una medida cautelar (Mercosur, 1994).

A estos instrumentos correspondería agregar, también en el Mercosur, el Acuerdo sobre el Beneficio de Litigar sin Gastos y la Asistencia Jurídica Gratuita entre los Estados Partes del Mercosur (decisión 49/00), que se encuentra en vigor entre Brasil y Paraguay, y el Acuerdo sobre el Beneficio de Litigar sin Gastos y la Asistencia Jurídica Gratuita entre los Estados Partes del Mercosur, la República de Bolivia y la República de Chile (decisión 50/00) (Mercosur, 2000b; 2000c), vigente entre Brasil, Paraguay y Chile. En ambas fuentes normativas, previo énfasis en «la fundamental importancia del establecimiento de mecanismos que permitan el efectivo acceso a la justicia» y teniendo presente lo dispuesto en la Convención Americana sobre Derechos Humanos (OEA, 1969), se prevé:

Los nacionales, ciudadanos y residentes habituales de cada uno de los Estados Partes gozarán, en el territorio de los otros Estados Partes, en igualdad de condiciones, de los beneficios de litigar sin gastos y de la asistencia jurídica gratuita concedidos a sus nacionales, ciudadanos y residentes habituales. (Artículo 1.)

Asimismo, el referido texto reconoce la eficacia extraterritorial del beneficio de litigar sin gastos concedido en el Estado parte requirente en un proceso en el que se soliciten medidas cautelares, recepción de pruebas en el extranjero y cualesquiera otras medidas de cooperación tramitadas mediante exhortos o cartas rogatorias en el 
Estado parte requerido (artículo 4) o donde se presente una sentencia para su reconocimiento (artículo 5). Por último, los Estados partes se comprometen a prestar asistencia jurídica gratuita a las personas que gocen del beneficio de litigar sin gastos, en igualdad de condiciones con sus nacionales o ciudadanos (artículo 9).

No podría cerrarse este apartado sobre el derecho de acceso a la justicia, sin hacer una breve referencia a la reciente aprobación de los Principios ASADIP sobre el acceso transnacional a la justicia. Se trata de un instrumento aprobado en 2016 por la Asociación Americana de Derecho Internacional Privado (ASADIP), entidad creada en 2007 que congrega a los especialistas de derecho internacional privado de América. El instrumento prevé su aplicación cuando las partes «hayan acordado que los aspectos procesales de su relación jurídica se rijan por ellos, a menos que dicho acuerdo se encuentre expresamente prohibido por el ordenamiento jurídico del foro» y los principios son aplicables también «a la interpretación, integración y complementación de las reglas que resulten competentes para regir esta materia».

El primero de dichos principios es el de «máximo respeto de los derechos humanos y acceso a la justicia» (artículo 1.1, literal $a$ ). Además, el capítulo 2, consagrado al tratamiento del litigante foráneo y la asistencia jurídica subvencionada, descarta la exigencia de garantías a ciudadanos extranjeros o residentes foráneos cuando este sea el único fundamento de dicha exigencia, y prevé la asistencia jurídica gratuita o subvencionada en favor de nacionales y extranjeros o residentes foráneos (ASADIP, 2016).

\section{Reflexión final}

La nueva realidad de las migraciones internacionales, que enfrenta al mundo a una realidad multicultural, constituye un desafío para el derecho internacional privado y las conexiones consagradas tradicionalmente por las normas de conflicto. Si bien las respuestas más recientes de esta disciplina en lo que hace a la regulación del estatuto personal parecen converger hacia soluciones más objetivas e inclusivas, los Estados, tanto en el ámbito convencional como nacional, deberán continuar buscando caminos de mayor flexibilidad que permitan el reconocimiento de nuevas modalidades familiares y el afianzamiento de las garantías procesales de los extranjeros, así como que la norma de conflicto - herramienta fundamental del derecho internacional privado-, a través de la localización de la ley aplicable y la jurisdicción competente mediante el punto de conexión, permita acercarse cada vez más al objetivo de justicia que logre hacer efectiva la protección de los derechos humanos de los migrantes. 


\section{Bibliografía}

ALFOnSín, Q. (1982). Teoría del derecho privado internacional. Montevideo: Idea.

ASADIP (2016). Principios ASADIP sobre el acceso transnacional a la justicia (Transjus).

Recuperado de http://www.asadip.org/v2/wp-content/uploads/2018/08/ ASADIP-TRANSJUS-ES-FINAL18.pdf.

BATIFFol, H. \& LAGARDE, P. (1981). Droit international privé: t. I. (7. a ed.). París: Librairie Générale de Droit et de Jurisprudence.

Boggiano, A. (1981). Del viejo al nuevo derecho internacional privado. Buenos Aires: Depalma.

Conference de la Haye De Droit International Prive (2018a). Filiation/Maternité de substitution. Recuperado de https://www.hcch.net/fr/projects/legislativeprojects/parentage-surrogacy.

Conference de la Haye de Droit International Prive (2018b). Cohabitation hors mariage, Projets. Recuperado de https://www.hcch.net/fr/projects/legislativeprojects/cohabitation.

Convención de Derecho Internacional Privado (s.f.). Código de derecho internacional privado: Código de Bustamante. Recuperado de https://www.oas.org/ juridico/spanish/mesicic3_ven_anexo3.pdf.

Couture, E. J. (1997). Vocabulario jurídico. Buenos Aires: Depalma.

DEPREZ, J. (1988). Droit international privé et conflits de civilisations: Aspects méthodologiques. Boston: Brill. (Collected Courses of the Hague Academy of International Law, 211).

ESTEBAN DE LA Rosa, G. (2007). «El nuevo derecho internacional privado de la inmigración». Revista Española de Derecho Internacional, 59(1), 103-129.

Hague Conference on Private International Law (2008a). Estatuto de la Conferencia de La Haya de Derecho Internacional Privado. Recuperado de https://www. hcch.net/es/instruments/conventions/full-text.

Hague Conference on Private International LaW (2008b). Convenio de 24 de octubre de 1956 sobre Ley Aplicable a las Obligaciones Alimenticias respecto a Menores. Recuperado de https://www.hcch.net/es/instruments/conventions/full-text/ ?cid=37.

Hague Conference on Private International LaW (2008c). Convenio de 5 de octubre de 1961 sobre Competencia de Autoridades y Ley Aplicable en Materia de Protección de Menores. Recuperado de https://www.hcch.net/es/instruments/ conventions/full-text/?cid=39.

Hague Conference on Private International Law (2008d). Convenio de 5 de octubre de 1961 sobre los Conflictos de Leyes en Materia de Forma de las Disposiciones Tes- 
tamentarias. Recuperado de https://www.hcch.net/es/instruments/ conventions/full-text/?cid=40.

Hague Conference on Private International Law (2008e). Convenio de 15 de noviembre de 1965 sobre Competencia de Autoridades, Ley Aplicable y Reconocimiento de Decisiones en Materia de Adopción. Recuperado de https://www.hcch.net/ es/instruments/conventions/full-text/?cid=75.

Hague Conference on Private International LaW (2008f). Convenio de 14 de marzo de 1978 sobre Ley Aplicable a los Regímenes Matrimoniales. Recuperado de https://www.hcch.net/es/instruments/conventions/full-text/?cid=87.

Hague Conference on Private International LaW (2008g). Convenio de 23 de noviembre de 2007 sobre Cobro Internacional de Alimentos para los Niños y Otros Miembros de la Familia. Recuperado de https://www.hcch.net/es/instruments/ conventions/full-text/?cid=131.

Hague Conference on Private International LaW (2008h). Convenio de 19 de octubre de 1996 Relativo a la Competencia, la Ley Aplicable, el Reconocimiento, la Ejecución y la Cooperación en materia de Responsabilidad Parental y de Medidas de Protección de los Niños. Recuperado de https://www.hcch.net/es/instruments/ conventions/full-text/?cid=70.

Hague Conference on Private international Law (2008i). Convenio de 25 de octubre de 1980 para Facilitar el Acceso Internacional a la Justicia. Recuperado de https://www.hcch.net/es/instruments/conventions/full-text/?cid=91 .

HoBsBawm, E. (2016). La era del capital: 1846-1875. (6. ${ }^{a}$ ed.). Buenos Aires: Crítica.

JAYME, E. (1995). Identité culturelle et intégration: le droit international privé postmoderne. Cours général de droit international privé. Boston: Brill. (Collected Courses of the Hague Academy of International Law, 211).

Ley 15.985 (1988). Código General del Proceso. Recuperado de https:// parlamento.gub.uy/documentosyleyes/leyes/ley/15982?width=800\&height= $600 \&$ hl=en_US1\&iframe=true\&rel=nofollow.

Ley 18.250 (2008). Migración. Recuperado de https://parlamento.gub.uy/ documentosyleyes/leyes/ley/18250?width=800\&height=600\&hl=en_US1\& iframe=true\&rel=nofollow.

Ley 10.084 (1941). Código Civil: se agregan varios artículos, como apéndice del título final. Recuperado de https://parlamento.gub.uy/documentosyleyes/leyes/ ley $/ 10084$ ? width=800\&height=600\&hl=en_US1\&iframe=true\&rel=nofollow.

Ley № 18.895 (2012). Restitución de Personas Menores de Dieciséis Años Trasladadas o Retenidas Ilícitamente. Recuperado de https://parlamento.gub.uy/ documentosyleyes/leyes/ley/18895?width=800\&height=600\&hl=en_US1\& iframe=true\&rel=nofollow. 
Mercosur (1992). Protocolo de Cooperación y Asistencia Jurisdiccional en Materia Civil, Comercial, Laboral y Administrativa. Recuperado de https://normas. mercosur.int/simfiles/normativas/DEC_005-

1992_ES_Prot.de\%20Coop \%20y\%20Asist.Jurisdiconal.pdf.

Mercosur (2000a). Acuerdo sobre Exención de Traducción de Documentos Administrativos para Efectos de Inmigración entre los Estados Partes del MERCOSUR, la República de Bolivia y la República de Chile (Decisión - 045/2000). Recuperado de http://gd.mercosur.int/SAM\%5CGestDoc\%5Cpubweb.nsf/42E66CFE24F6C3A0 03258350003E180D/\$File/DEC_045-

2000_ES_FERR_Acuerdo $\% 20 \% 20$ Exenci $\%$ C2 $\%$ A2n_Trad-

Docum_Inmigraci\%C2\%A2n_MCS_BOLCHI_Acta\%202_00.pdf.

Mercosur (2000b). Acuerdo sobre el Beneficio de Litigar sin Gastos y Asistencia Jurídica Gratuita entre los Estados Partes del MERCOSUR. Recuperado de https://normas.mercosur.int/simfiles/normativas/DEC_049-

2000_ES_FERR_Acuerdo_Benef-Justicia_Asist-Jur_Gratuita_Acta\%202_00.pdf.

MERCOSUR (2000c). Acuerdo sobre el Beneficio de Litigar sin Gastos y Asistencia Jurídica Gratuita entre los Estados Partes del MERCOSUR, la República de Bolivia y la República de Chile. Recuperado de https://normas.mercosur. int/simfiles/normativas/DEC_050-2000_ES_FERR_Acuerdo_Benef-Justicia_AsistJur_Gratuita_MCS_BOLCHI_Acta\%202_00.pdf.

Mercosur (2002). Acuerdo de Cooperación y Asistencia Jurisdiccional en Materia Civil, Comercial, Laboral y Administrativa entre los Estados Partes del MERCOSUR y la República de Bolivia y la República de Chile. Recuperado de https://normas.mercosur.int/simfiles/normativas/DEC_008-

2002_ES_Acuerdo_Asist_Civil_Lab.Com_y\%20Administ_MCS-Acta\%201_02.pdf.

Mercosur (2004). Protocolo de Ouro Preto (Adicional al Tratado de Asunción sobre la Estructura Institucional del MERCOSUR). Recuperado de https://www.mercosur. int/documento/protocolo-ouro-preto-adicional-tratado-asuncion-estructurainstitucional-mercosur/.

OEA (s.f.a). Convención Interamericana sobre Domicilio de las Personas Físicas en el Derecho Internacional Privado. Recuperado de http://www.oas.org/juridico/ spanish/tratados/b-44.html.

OEA (s.f.b). Convención Interamericana sobre Obligaciones Alimentarias. Ámbito de Aplicación. Recuperado de http://www.oas.org/juridico/spanish/tratados/b54.html.

OEA (s.f.c). Convención Interamericana sobre Exhortos o Cartas Rogatorias. Recuperado de https://www.oas.org/dil/esp/CIDIPI_doc_exhortos.htm. 
OEA (s.f.d). Protocolo Adicional a la Convención Interamericana sobre Recepción de Pruebas en el Extranjero. Recuperado de http://www.oas.org/juridico/spanish/ tratados/b-51.html.

OEA (s.f.e). Convención Interamericana sobre Cumplimiento de Medidas Cautelares. Recuperado de http://www.oas.org/juridico/spanish/tratados/b-42.html.

OEA (1969). Convención Americana sobre Derechos Humanos (Pacto de San José). Recuperado de https://www.oas.org/dil/esp/tratados_B-32_Convencion_Americana_ sobre_Derechos_Humanos.pdf.

OEA (2015). Declaración Americana de los Derechos y Deberes del Hombre: Aprobada en la Novena Conferencia Internacional Americana. Bogotá, Colombia, 1948. Recuperado de http://www.oas.org/es/cidh/mandato/Basicos/declaracion.asp.

OIM (2006). «Glosario sobre migración». Derecho Internacional sobre Migración, 7, 186.

OIM (2018). World Migration Report 2018. Ginebra: OIM.

ONU (1948). Declaración Universal de los Derechos del Hombre. Recuperado de https://undocs.org/es/A/RES/217(III).

ONU (1957). Final act of the United Nations Conference on Maintenance Obligations and Convention on the Recovery Abroad of Maintenance, done at New York on 20 June 1956. Recuperado de https://assets.hcch.net/docs/d759a41f-548d-447c-9d9a2ca91093f60a.pdf.

ONU (1966). Pacto Internacional de Derechos Civiles y Políticos. Recuperado de https://undocs.org/es/A/RES/2200(XXI).

ONU (1985). Declaración sobre los Derechos Humanos de los Individuos que no son Nacionales del País en el que Viven. Resolución 40/144. Recuperado de https://undocs.org/es/A/RES/40/144.

ONU (1990). Convención Internacional sobre la Protección de los Derechos de Todos los Trabadores Migratorios y de sus Familiares. Recuperado de https://undocs.org/ es/A/RES/45/158.

ONU (1999). Recomendaciones sobre estadísticas de las migraciones internacionales: Revisión 1. Nueva York: ONU. (Informes Estadísticos, serie M, n. ${ }^{\circ}$ 58, rev. 1).

ONU (2000a). Declaración del milenio. Resolución 55/2. Recuperado de https://undocs.org/es/A/RES/55/2.

ONU (2000b). Convención de las Naciones Unidas contra la Delincuencia Organizada Transnacional. Recuperado de https://undocs.org/es/A/RES/55/25.

UNDP (2004). Access to Justice: Practice note. Recuperado de: http://www.undp.org/ content/dam/aplaws/publication/en/publications/democratic-governance/dgpublications-for-website/access-to-justice-practice-note/Justice_PN_En.pdf.

SavignY, F.C. Von (2004). Sistema do direito romano atual: Vol. VIII. Ijuí: Unijuí. 
Tellechea Bergman, E. (2011). «Cuestiones procesales vinculadas a los casos privados internacionales de familia y minoridad en el ámbito interamericano y del Mercosur». Boletín Mexicano de Derecho Comparado, 44(132), 1171-1231. Recuperado de http://www.scielo.org.mx/pdf/bmdc/v44n132/v44n132a6.pdf.

Tratado de derecho civil internacional: Montevideo, 12 de febrero de 1889 (s.f.). Recuperado de https://sociedip.files.wordpress.com/2013/12/tratado-de-montevideode-1889.pdf.

Tratado de Montevideo de 1940 sobre derecho civil internacional (s.f.). Recuperado de https://sociedip.files.wordpress.com/2013/12/tratado-de-monttevideo-de1940.pdf.

Unión EuRopeA (23 de diciembre, 2003). «Reglamento (CE) n. 2201/2003 del Consejo, de 27 de noviembre de 2003, relativo a la competencia, el reconocimiento y la ejecución de resoluciones judiciales en materia matrimonial y de responsabilidad parental, por el que se deroga el Reglamento (CE) n. $.^{\circ} 1347 / 2000 »$. Diario Oficial de la Unión Europea, 338, 1-29. Recuperado de https://eur-lex. europa.eu/legal-content/ES/TXT/?uri=uriserv:OJ.L_.2003.338.01.0001.01.SPA\& toc=0J:L:2003:338:TOC.

Unión Europea (27 de julio, 2012). "Reglamento (UE) n. ${ }^{\circ}$ 650/2012 del Parlamento Europeo y del Consejo, de 4 de julio de 2012 , relativo a la competencia, la ley aplicable, el reconocimiento y la ejecución de las resoluciones, a la aceptación y la ejecución de los documentos públicos en materia de sucesiones mortis causa y a la creación de un certificado sucesorio europeo». Diario Oficial de la Unión Europea, 201, 107-134. Recuperado de https://eur-lex.europa.eu/legal-content/ ES/TXT/?uri=uriserv:OJ.L_.2012.201.01.0107.01.SPA.

VÉSCOVI, E. (2000). Derecho procesal civil internacional: Uruguay, el Mercosur y América. Montevideo: Idea. 